\title{
دوافع الطلاب في تعلم اللغة العربية و دور المعلم في ترقيتها
}

\section{Achmad Tito Rusady}

Dosen Prodi Pendidikan Bahasa Arab - Fakultas Agama Islam Universitas Muhammadiyah Malang

\section{Email: otitmaster@gmail.com}

\section{Abstract}

Learner of Arabic language still finds many difficulties in learning Arabic. It may be caused by motivation. The stronger motivation, the smaller difficulties and the weaker motivation, the greater difficulties. Many students can get their will and success no matter how many difficulties are, with strong motivation as the basis for success. Motivation is a manifestation of students' knowledge of the goals in work either by their own attempt or by instructing the teacher as their defensive role in promoting motivation.

\section{أ- - 20 - 20 - مقدمة}

$$
\begin{aligned}
& \text { الدافع هو إرادة الإنسان القوية لنيل غاية ما. فبدون } \\
& \text { الدافع لايقدر الإنسان على الحصيول إلى أمله. و لازم في التعلم } \\
& \text { أن يملك الطلبة الدافع القوي ليحصلوا على عملهم و أملهم. } \\
& \text { ولو كانت الصعوبات أو المشكلات التي سيواجهونها كبيرة و } \\
& \text { ثقيلة فليس عائقة لهم الذين عندهم الدافع و الحافز القوي. }
\end{aligned}
$$


فالإنسان له غرض معين في تنفيذ إرادته. لايقضي

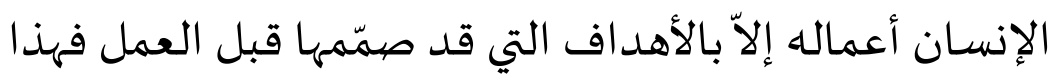

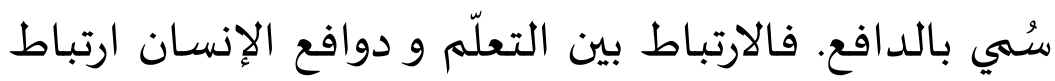
قوي، كانت دوافع الإنسان تجعل محاولته قوية. وقد كثر بأر

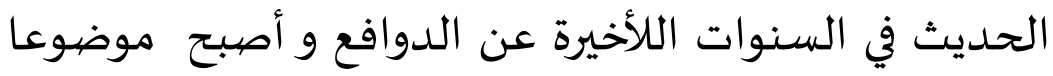

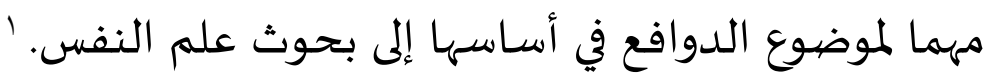

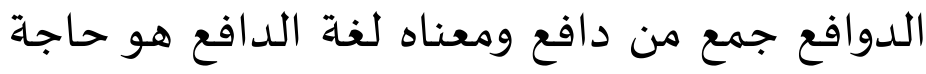
غير مشبعة يؤدي إلى سلوك معين للفرد، ويتحدد هذا

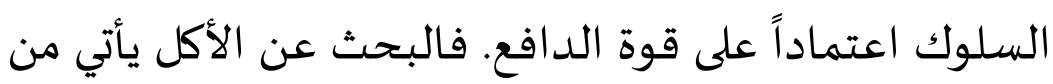
واقع طبيعي هو الجوع وبمجرد إشباع هذه الحاجة ينقضي

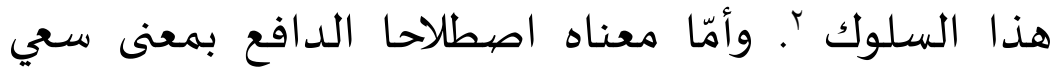
الإنسان لأن يتحرك و أن يفعل فعلا معينا لنيل غايته. وّمعنى هذا أنّ طبيعة الإنسان يستطيع أن يفعل أكثر مما يقوم بان أنهان

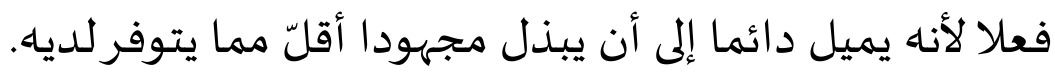
ومن أهمية الدوافع في التعليم هي الفعالية في عمليته

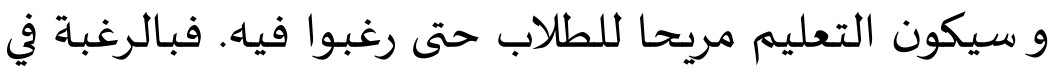
التعليم سوف يحصل الإنسان على النجاح. ولكنّ الآن لم تَزل

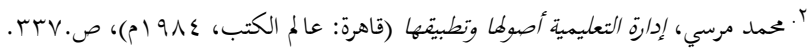

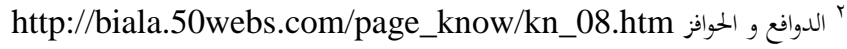
${ }^{3}$ Sardiman AM, Interaksi dan Motivasi Belajar Mengajar, (Jakarta: CV. Rajawali, 1990), p. 73-74. 
المشكلة موجودة في ترقية الدوافع عند التعليم ولم يكن اهتمامها اهتماما جيّدا. من أسبابها يعنى عدم الاهتمام بالمجال الانفعالي و غلبة المجال المعرفيّ كما حدث في معظم المدارس مع أن المجال الانفعالي مهمّ في ترقية الدوافع.ع

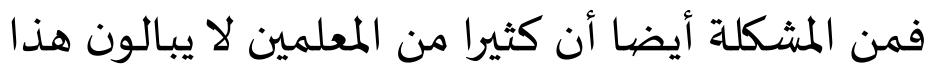
الجانب و هم بخلاء في إعطاء المدح و التحية للطالب الذي يناسب بهذا الترغيب. بل على العكس أن كثير من المعلمي أندونيسيا في فصلهم مجرد يتدربون و يغضبون أكثر فعلا من أن يمدحوا الطالب المتقدم في تعليمه.

$$
\begin{aligned}
& \text { ب- مفهوم الدوافع و أنواعها } \\
& \text { ا. مفهوم الدوافع }
\end{aligned}
$$

دوافع جمع من دافع ومعناه لغة الدافع هو حاجة غير مشبعة يؤدي إلى سلوك معين للفرد، ويتحدد هذا السلوك اعتماداً على قوة الدافع. فالبحث عن الأكل يأتي من واقع طبيعي هو الجوع وبمجرد إشباع هذه الحاجة ينقضي هذا السلوك '. وأمّا معناه صطلاحا الدافع هو السعي يدافع

${ }^{4}$ Satria Dharma, Unas: Pembangkangan Masal, (Jakarta: Harian Jawa Pos, Opini, 10 Mei 2011).

5 Acep Hermawan, Metodologi Pembelajaran Bahasa Arab, (Bandung: Rosdakarya), hlm. 35

http://biala.50webs.com/page_know/kn_08.htm المرجع السابق، 
الإنسان لأن يتحرك و يفعل فعلا لنيل غايتهـ. و أنّ طبيعة الإنسان يستطيع أن يفعل أكثر مما يقوم به فعلا لأناه يميل

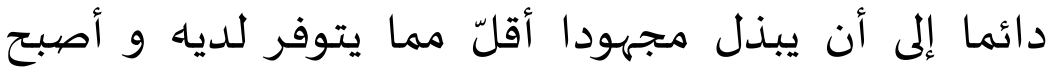

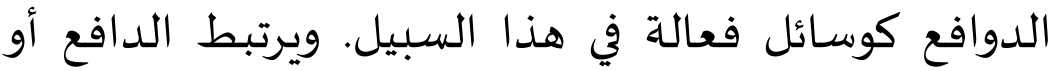
الحافز بالجزاء سواء كان عقاب أو ثوابا بهذا يكون هناك من حيث النوع ينقسم الدوافع إلى نوعين ^: الدوافع الإيجابية و

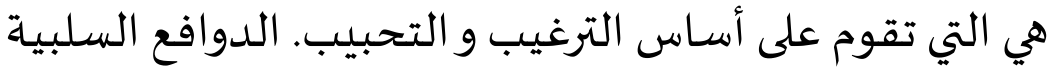
و هي التي تقوم على أساس التخويف و الترهيب.

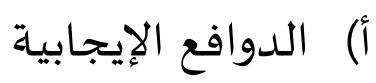

VictorH. ${ }^{9}{ }^{9}$ Vroom و أمّا المقصود من الرجاء في التعليم هو إعطاء الجزاء إلى الطلاب لترقية رغبتهم في التعلم كإعطاء النتيجة أو الجائزة أو الهداية أو الشهادة لمن يكون منهم الفائز.

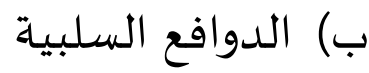

فتأخذ صوره العقاب بألوانه وأساليبه المختلفة المعنوية والمادية منها على السواء. ومنهما يبرزان سؤال طبيعي: أيهما

${ }^{7}$ Sardiman AM, Interaksi dan Motivasi Belajar Mengajar, (Jakarta: CV. Rajawali, 1990), p, 73-74.

$$
\text { ^حمد مرسي،المرجع السابق ، ص.rVV. }
$$

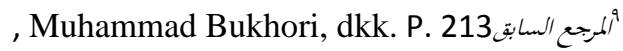


أجدى و أحسن؛ الدوافع الإيجابية أم الدوافع السلبية؟

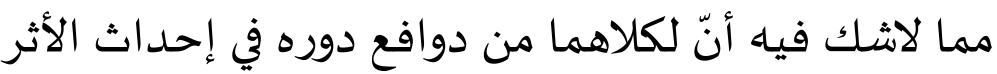
المنشودة و النتيجة المطلوبة. ولكل منهما أيضا موافقه واستعمالاته الخاصة. وقد يكون استخدام أحد النوعين

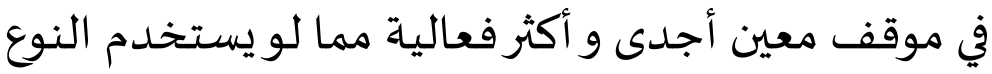
الثاني. و كلا هما أيضا يتمشى من طبيعة النفس الإنسانياة و مع ما أقرّته الشارائع السماوية من ثواب وعقاب لتهذيبها

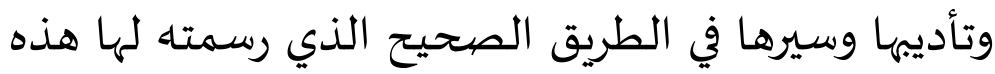
الشرائع.

ويتمشى أيضيا مع ما تسير عليه القوانين الوضعية والعرفية من الأخذ بلا الأسلوبين في تقويم السلوك البشري و دفعه في إطار النظام المرسوم كما تحدده هذه القوانين

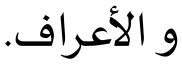

ومن هذا أنه يتضح المعنى الذي أردنا أن نؤكده وهو أن لكلا النوعين من دوافع تأثيره وفعاليتاه في تنظيم السلوك البشري في إطار معين.

\section{r. الفرق بين دوافع الإيجابية و دوافع السلبية}

أنّ هناك فرق بين النوعين على الرغم من إحداثهما نفس التأثير. نستعين ببعض النتائج المعروفة في علم النفس إنس إنى 
المستخلصة من واقع التجارب التي أجريت في هذا الميدان لدراسة أثركلّ من الثواب والعقاب في تغيير السلوك أوتعدارب التعدية. فنجد ثلاثة الحقائق '؛

1. أنّ كلا النوعين من الجزاء يحدث نفس الأثرو النتيجة

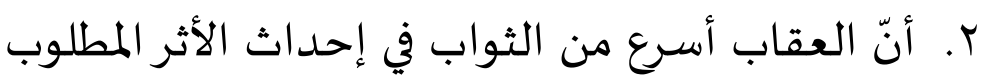

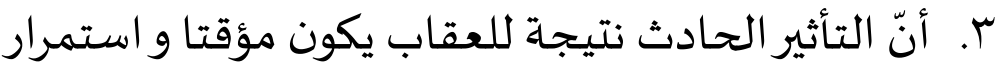

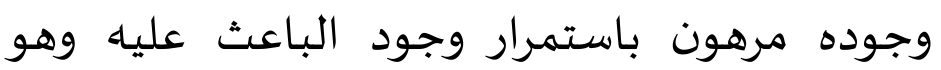

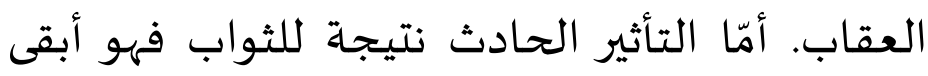

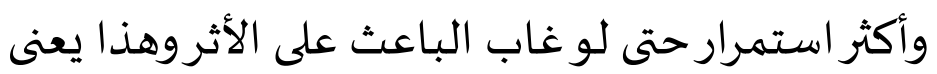

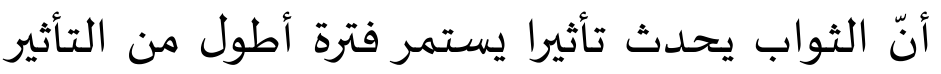

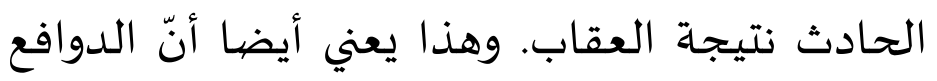
الإيجابية و الدوافع السلبية تحدثان نفس الأثر

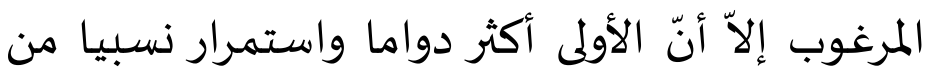

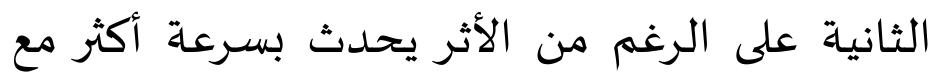

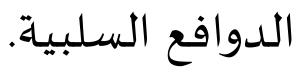

أ) الدوافع الإيجابية تتكوّن على النوعين: الدوافع الماديّة: هي أهمية المال في حياتنا المعاصرة كوسيلة هامة ضرويّة في تحقيق مطالبنا وحاجاتنا المعيشياة. 
الدوافح المعنويّة (غير المادية): وهي كلّ أنواع دوافح الأخرى غير المالية وترتبط هذه الأنواع من دوافع أيضا ارتباطا مباشرة بالحاجات النفسية و المعنوية لدى الإنسان. وتنقسم هذه الحاجات إلى قسمين:

حاجات أوليّة: وهي الحاجات البيلوجيّة و الفسيولوجياة مثل الحاجة إلى الطعام و الشراب و التنفس و الراحة وهي لحسي حاجات فطرية طبيعية يولد الإنسان مزوّدا بها وتتصل بتركيب الجسم ومساعدته على أداء وظائفه. حاجات ثانويّة: وهي حاجات مكسبة وليست فطريّة و إنما يتعلمها الإنسان خلال نموه احتكاكه بالبيئة و الوسط الاجتماعي الذي يعيش فيه مثل الحاجات إلى الاحترام و الحاجات إلى التقدير و الحاجات إلى المكانة الاجتماعية و

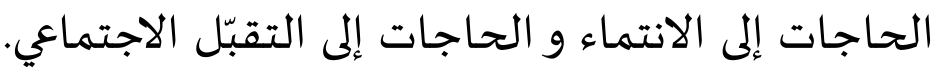

ب) عوامل الدوافع وأهميتها في الإدارة التعليمياة:

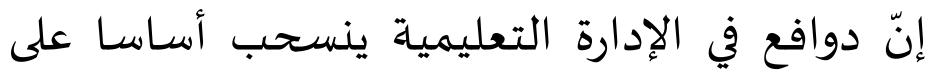

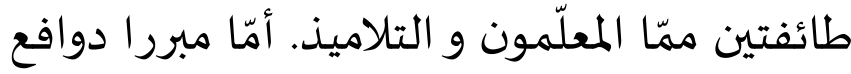
بالنسبة المعلمين فتقوم على أسـاس أن المعلّم هو حجر

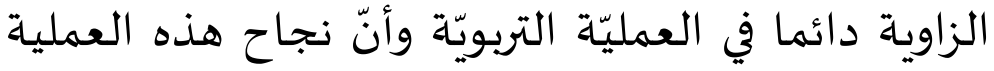


معتمد بالدّرجة الأولى على المعلم، وتقدّم التلاميذ في الفصل يعتمد على مدى كفاءة المعلم و إعداده الجيّد و إخلاصياء في عمله وحباه لله وتحمساء للمهنة.

من أساليب دوافع السلبية المعروفة بنوعيها المادي

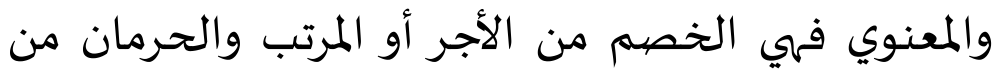

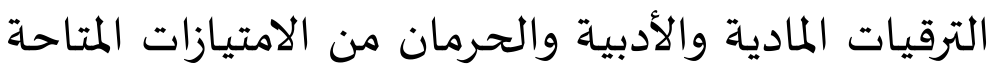
و اللوم ولفت النظر والتقديرات الضعيفة في التقارير الفنية والسرية والحرمان من الاشتراك في النشاط المدرسي وماشاباه ذلك.

من أساليب دوافع الإيجابية المعروفة بنوعيها

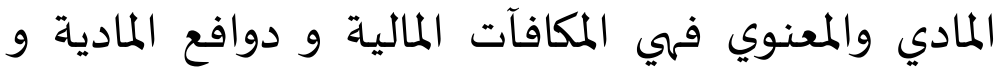
إعطاؤهم الأولوية في الامتيازات المتاحة و في التنقلات و الإعارات والترقيات الأدبية والمادية ومنحهه أقدميات الاتيات اتباريّة عن عملهم المتميّز وتكريم الممتازين منهم في احتفالات عيد العلم أو يوم المعلم ومنحهم شهادات تقدير أو أنواط الواجب والمواطنة الصالحة وغيلة المعيرها.

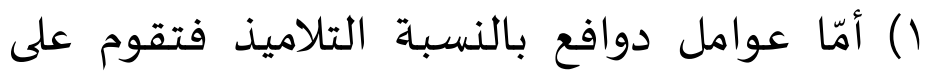
أسساس واقع المشكلات التعليمية و في مقدمتها باسها صعوبة عملية التعلم وعدم أقبال و انتظام كثير 
من التلاميذ لاسيما في المرحلة الابتدائيّة. وتصبح دوافع عوامل بديله للتغلب على هذه العوامل المثبطة وحفز التلاميذ على الغلب على صعوبات الدراسة ومشكلاتها.

من أساليب دوافع السلبية فهي اللّوم والتأديب والانذاروالفصل والحرمان من الإمتيازات والغرامات. من أساليب دوافع الإيجابية فأهما مكافأة أوائل الناجحين و إعطاؤهم شهادات تقدير ومنحهم الاهم الإمتيازات أو تقديم وجبة غذاندائية أو الأعضاء من الرسوم الإضافية.

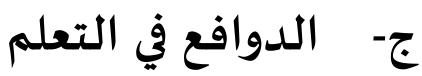

من حيث أساس ينقسم الدوافح إلى ثلاثة أقسام" 1) الدافع الفطري (Biogenetis) : هو الدافع الذي قد الد وقع في نفس الإنسان منذ وجوده كالإرادة للأكل العل و الشرب و العمل و غيرها .

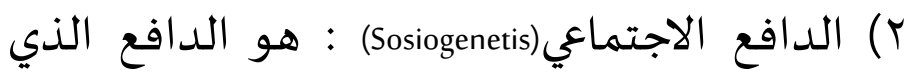

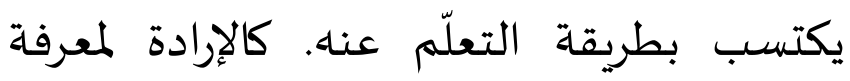

11 H. Nashar, Peranan Motivasi dan kemampuan Awal, (Jakarta: Deloa Press,2004), p. 22

Jurnal Izdihār : Journal of Arabic Language Teaching, Linguistics, and Literature 
العلوم المعينة ولذلك يستطيع الإنسان أن يعلم

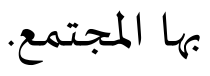

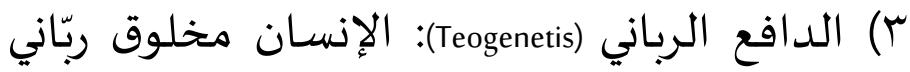

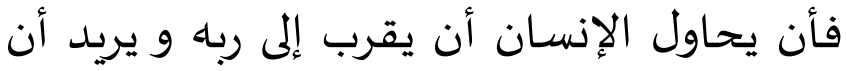

يعبده و أن يطلب من ربه الهداية و النجاة من

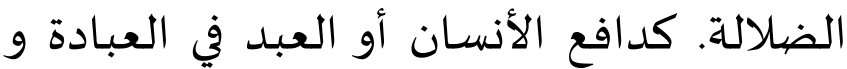

تنفيذ شعائر الله و سنن الرسول.

من حيث الصفة ينقسم الدافع إلى قسمين:

() الدافع الداخلي (Instrinsik): الدافع الذي يصدئ من

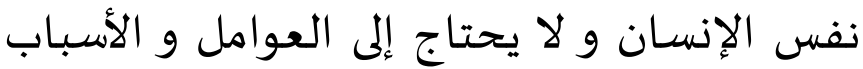

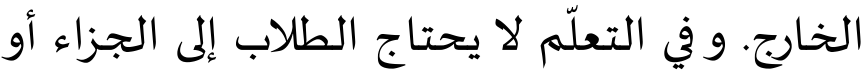

الخوف عن العقاب بل هم يدرسون المادة برغبتهم

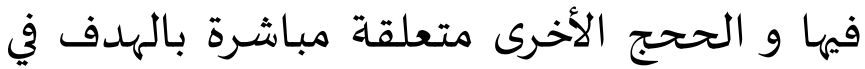

التعليم.

r (Ekstrinsik): عكس الدافع الدع الداخلي و هو الدافع الذي جاء من خارج شخصية الإنسان و ليس له العلاقة المباشرة بالهدف في التعليم.

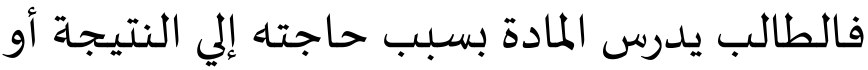

12 Alisuf Sabri. Psikologi Pendidikan Berdasarkan Kurikulum Nasional, (Jakarta: CV.Pedoman Ilmu, 1995), p. 85 
الجزاء أو الشهادة و كذلك يخاف عن العقاب أو

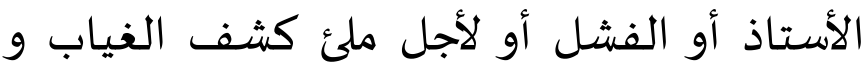

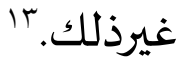

د- دور المعلم في ترقية دوافع الطلبة في تعلم اللغة العربية

ويبرز من المعلومات السابقة الاهتمام إلى المجال الدافعية لدى الطلبة في تعلم اللغة العربية. مما يظهر الواقع أن حماسة الطلبة في تعلم اللغة العربية أدنى من أن يتعلم

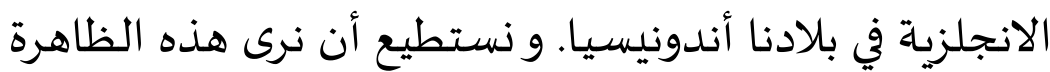
في بعض المناطق في سومطرى. أن الطلاب في شعبة تعليم اللغة العربية أقل عددا من الطلاب في شعبة تعليم اللغة الانجليزية. مع أن حسب نظر الكاتب هذه الجامعة الجامعة الجات الإسلامية الحكومية. فكيف يكون عددهم قليلا؟

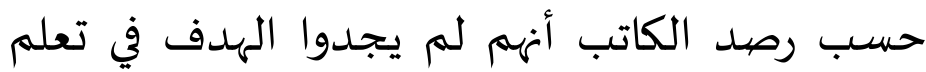
اللغة العربية. وجد الكاتب أن بعض الطلبة في إحدى الجامعة بسومطرى له يجد حجة قوية حين يسأل لماذا اخترت الدخول إلى شعبة اللغة العربية؟ فلذلك لابد أن يكون

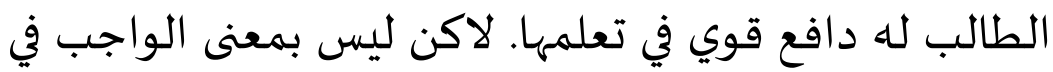

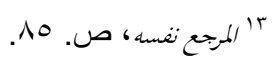


هذا الأمر من جانب الطالب فحسب بل على المعلمين ينبغي

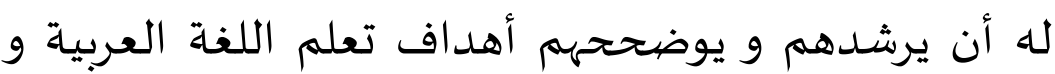

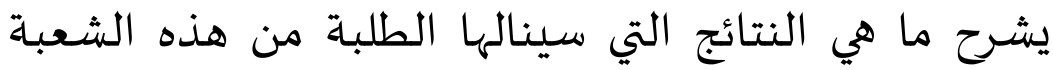

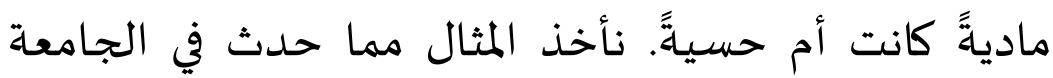
مولانا مالك إبراهيم الإسلامية الحكومية بمالانج في البرنامج المانه

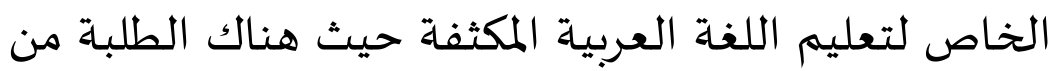
شعبة الهندسة يحب عليهم أن يشتركوا في هذا البرنامج.

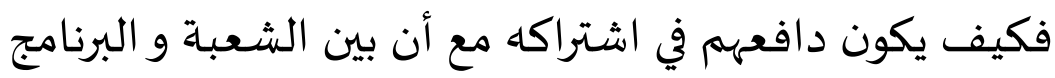

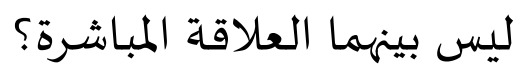
فظهر التحليل من البحث العلمي في تلك المشكلة تحت المبات

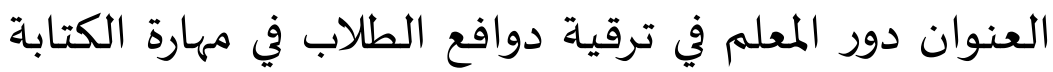
دراسة وصفية تقويمية بالبرنامج الخاص لتعليم اللغة العربية لطلاب قسم الهندسة بجامعة مولانا مالك إبراهيم الإسلامية

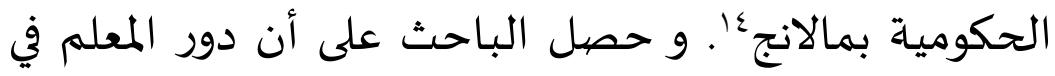

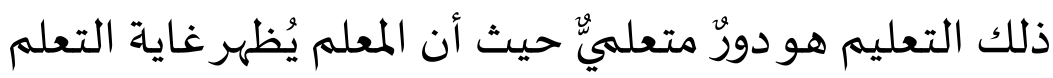
و يربط المادة بالحوادث اليومية و يتطبق التعليم التعاوني و

؛' أحمد تينو رشادي، دور المعلم في ترقية دوافع الطلاب في مهارة الكتابة دراسة

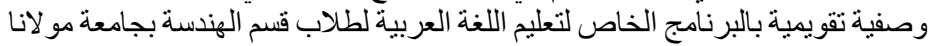

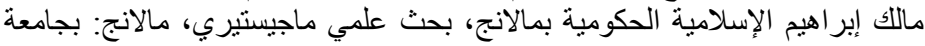

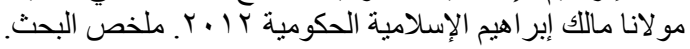


يتطبق اللعبـة اللغوية و المعاملة الحسنة و التقويم. من تلك المحاولات يستطيع الطلبة ان يتعلموا بالمريح و الهمّة جيدة. و هكذا ينبغي للمعلم أن يتهم الجانب الدافعي لدى

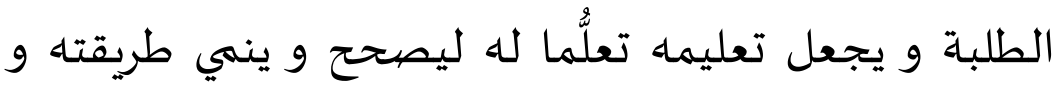
تربيته في الفصل.

\section{المراجع}

أحمد تيتو رشادي، بحث علمي دور المعلم في ترقية دوافع الطلاب في مهارة الكتابة دراسـة وصفية تقويمية بالبرنامج الخاص لتعليم اللغة العربية لطلاب قسم الهندسـة بجامعة مولانا مالك إبراهيم الإسـلامية

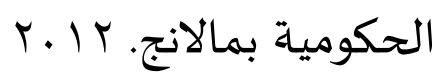
محمد مرسي، إد/رة التعليمية أصبولها وتطبيقها ، قاهرة:

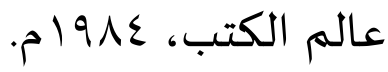
http://biala.50webs.com/page_know/kn_08.htm الدوافع و الحوافز AM, Sardiman. Interaksi dan Motivasi Belajar Mengajar, Jakarta: CV. Rajawali, 1990.

Bukhori, Muhammad. dkk. Azas-Azas Manajemen, Yogyakarta: Aditya Media. 2005.

Hermawan, Acep. Metodologi Pembelajaran Bahasa Arab, (Bandung: Rosdakarya). 
Meleong, Lexy J. Metodologi Penelitian Kualitatif, Jogjakarta: PT. Remaja Rosda Karya, 2003.

Nashar, H. Peranan Motivasi dan kemampuan Awal, Jakarta: Delia Press, 2004.

Unas: Pembangkangan Masal, Jakarta: Harian Jawa Pos, Opini, 10 Mei 2011.

Sabri, Alisuf. Psikologi Pendidikan Berdasarkan Kurikulum Nasional, Jakarta: CV.Pedoman Ilmu, 1995. 